cognitive factors. Of the two indices tested, speed and accuracy, only accuracy showed an age and drug effect. Nitrazepam depressed motor function irrespective of age while its depressive effects on cognitive function were greater in the elderly. Clinically this is borne out by a syndrome described only in elderly people, in which considerable confusion and disorientation result from chronic administration of nitrazepam. ${ }^{17}$ This increased sensitivity of the ageing brain to the action of nitrazepam can most readily be explained on present evidence by a change in the normal compensatory mechanisms. ${ }^{21}$ The fact that the elderly performed less well overall in the psychomotor test than the young, even on placebo, reflects a general deterioration that accompanies ageing, especially when speed of performance is emphasised. ${ }^{22}$

Malpas et $a^{23}$ have shown psychomotor impairment the next morning and electroencephalogram abnormalities up to 18 hours after a single dose of nitrazepam. Our results suggest that the effects of this drug last considerably longer, however-even up to 60 hours after a single dose. This is not surprising in view of the long half life, which makes it unlikely that sleep can be induced without producing side effects the next day. The effects of repeated doses remain to be studied, but the mean steady state concentration of nitrazepam calculated from our data would have produced considerable adverse effects in our subjects unless tolerance occurred.

In conclusion, our findings support the concept that the dose of nitrazepam should be decreased in elderly patients but suggest that this is due to a change in the ageing brain and not a change in pharmacokinetics, as has been suggested.
We thank Dr L Arenillas for his helpful comments and Dr Oakley John for allowing us to study the elderly patients under his care. The project was supported by a grant from Roche Products Limited.

\section{References}

${ }^{1}$ Hurwitz, N, British Medical fournal, 1969, 1, 536.

2 Kato, R, and Takanaka, A, Fapanese fournal of Pharmacology, 1968, 18, 389.

3 Kato, R, and Takanaka, A, Fapanese fournal of Pharmacology, 1968, 18, 381.

4 O'Malley, K, et al, British Medical fournal, 1971, 3, 607.

5 Jori, A, Di Salle, E, and Quadri, A, Pharmacology, 1972, 8, 273.

${ }^{6}$ Irvine, R E, et al, British fournal of Clinical Pharmacology, 1974, 1, 41.

7 Vestal, R E, et al, Clinical Pharmacology and Therapeutics, 1975, 18, 425.

${ }^{8}$ Davies, D F, and Shock, N W, Fournal of Clinical Investigation, 1950, 29, 496.

${ }^{9}$ Brod, J, Scripta Medica, 1968, 41, 223.

${ }^{10}$ Smith, T W, and Haber, E, fournal of Clinical Investigation, 1970, 49, 2377.

11 Harman, J B, Prescribers' fournal, 1971, 11, 142.

12 Chouinard, G, Modern Geriatrics, 1975, 5, 2.

${ }_{13}$ Hall, M R P, New York State fournal of Medicine, 1975, 75, 67.

14 de Silva, J A F, and Bekersky, I, fournal of Chromatography, 1974, 99, 447.

15 MIMS, 1976, 18, 50

${ }_{16}$ Rieder, J, Arzneimittel-Forschung, 1973, 23, 212.

17 Evans, J G, and Jarvis, E H, British Medical fournal, 1972, 4, 487.

18 Boston Collaborative Drug Surveillance Program, New England fournal of Medicine, 1973, 288, 277.

19 Klotz, O, et al, fournal of Clinical Investigation, 1975, 55, 347.

${ }^{20}$ Bond, A J, and Lader, M H, Psychopharmacologia, 1972, 25, 117.

${ }^{21}$ Rawlins, M D, British fournal of Hospital Medicine, 1974, 12, 803.

22 Anastasi, A, Differential Psychology, 3rd edn. New York, Macmillan, 1958.

${ }^{23}$ Malpas, A, et al, British Medical fournal, 1970, 2. 762.

\title{
Antimicrobial proteins in sterilised human milk
}

\author{
MARIA RAPTOPOULOU-GIGI, K MARWICK, D B L MCCLELLAND
}

British Medical fournal, 1977, 1, 12-14

\section{Summary}

Human milk contains factors such as IgA and lactoferrin that increase the newborn infant's resistance to infection. Preterm infants are fed pooled milk, which is normally sterilised by heating. After standard heat sterilisation IgA and lactoferrin were undetectable in milk samples. Pasteurisation also sterilised milk samples even after heavy artificial contamination and did not damage the proteins. Gamma-irradiation sterilised equally effectively but caused some denaturation of $\operatorname{IgA}$ and lactoferrin. Since most of the milk samples were sterile or had only light contamination with skin bacteria, there seems to be no need for routine sterilisation. If sterilisation is necessary, the method used should be chosen to minimise damage to milk proteins.

\footnotetext{
University Department of Therapeutics, Royal Infirmary, Edinburgh MARIA RAPTOPOULOU-GIGI, MB, research associate (present address: "B" Medical Department, Aristotelian University of Salonika, Greece)

K MARWICK, FIMLS, senior technician

D B L MCCLELLAND, MB, MRCP, lecture
}

\section{Introduction}

The breast-fed infant appears to have greater resistance to infection than the artificially fed child. ${ }^{1}$ Hence it is logical to use human milk to feed infants who are particularly at risk of infection. It is common practice to feed pooled expressed breast milk to preterm babies, ${ }^{2}$ and it is desirable that these infants should receive the milk with its protective properties intact. To obtain information about the effect of a standard sterilisation procedure on milk proteins we examined the effect on two proteins (IgA and lactoferrin) known to have important antimicrobial functions. Antibody titres to Escherichia coli were also measured, and the effects of alternative methods of sterilisation were investigated.

\section{Methods}

Samples of human milk obtained by manual expression or the Humalactor breast pump during routine collections on the wards were obtained from the central milk kitchen of the Simpson Memorial Maternity Pavilion. Part of each sample was sterilised in the standard way by heating to $105^{\circ} \mathrm{C}$, freezing, and thawing, the cycle then being repeated. Part of the remainder was stored at $-40^{\circ} \mathrm{C}$ for immunological studies after bacteriological cultures had been made using blood agar, McConkey agar, and mannitol salt agar plates. Aliquots of the unsterilised samples were stored at room temperature for a maximum of six hours before being subjected to pasteurisation $\left(62.5^{\circ} \mathrm{C}\right.$ for 30 minutes) or gamma-irradiation with $2.5 \mathrm{Mrads}$ from a cobalt- 60 source. The samples were cultured again within one hour 
of pasteurisation and within three hours of irradiation and an aliquot of the processed sample was stored at $-40^{\circ} \mathrm{C}$.

In a further experiment fresh samples were deliberately contaminated with Staphylococcus aureus and E coli 012 (about $2 \times 10^{7}$ organisms $/ \mathrm{ml}$ ) and incubated for two hours at room temperature. These samples were then cultured before and after pasteurisation.

IgA and lactoferrin were detected qualitatively by double gel diffusion and concentrations measured by single radial immunodiffusion. The standards for IgA and human lactoferrin were prepared by the method of Newcomb et al. ${ }^{3}$ Anti-IgA serum was obtained from Hoechst Pharmaceuticals and antilactoferrin serum prepared by immunising rabbits with purified lactoferrin in Freund's complete adjuvant. Immunoelectrophoresis slides were developed with antiserum to whole human colostrum prepared in the same manner. This antiserum was used in immunoelectrophoresis as it reacts not only with lactoferrin and IgA but also with several other milk proteins. Examination of the immunoelectrophoretic patterns thus gave qualitative information about the effects of processing on these milk constituents. Haemagglutination titres against pooled $E$ coli $\mathrm{O}$-antigens were determined by a micromethod. ${ }^{4}$

\section{Results}

Bacterial contamination and effectiveness of sterilisation-Most of the samples received were sterile or contained only a light growth of Staph albus and $\alpha$-haemolytic streptococci (table I). Two samples taken with the pump contained $E$ coli. The standard sterilisation procedure, gamma-irradiation, and pasteurisation sterilised all the samples received. Pasteurisation also sterilised all the samples that were deliberately heavily contaminated with Staph aureus and $E$ coli. The effect of the other procedures on these samples was not tested.

$\operatorname{Ig} A$ and lactoferrin levels before and after sterilisation-After conventional sterilisation neither IgA nor lactoferrin could be detected in any sample (table II) and the immunoelectrophoretic pattern was grossly changed (see figure, $a$ ). Gamma-irradiation produced a slight fall in IgA levels, and a substantial drop in lactoferrin levels. The appearance of the IgA arc on immunoelectrophoresis was changed after irradiation, indicating partial denaturation (figure, $b$ ). Pasteurisation did not change the mean levels of IgA or lactoferrin. In four samples there was an apparent rise in lactoferrin concentration, which was probably due to partial denaturation, yielding antigenic fragments

TABLE 1-Effectiveness of different methods of sterilising human milk

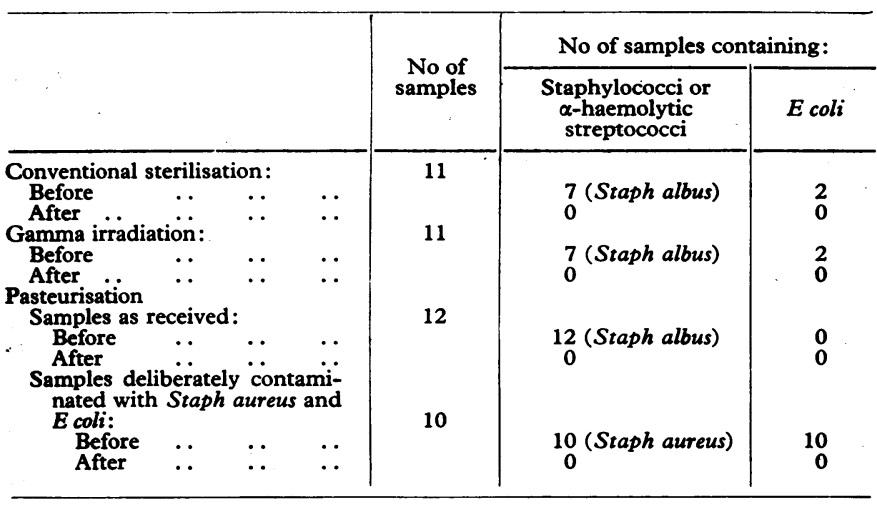

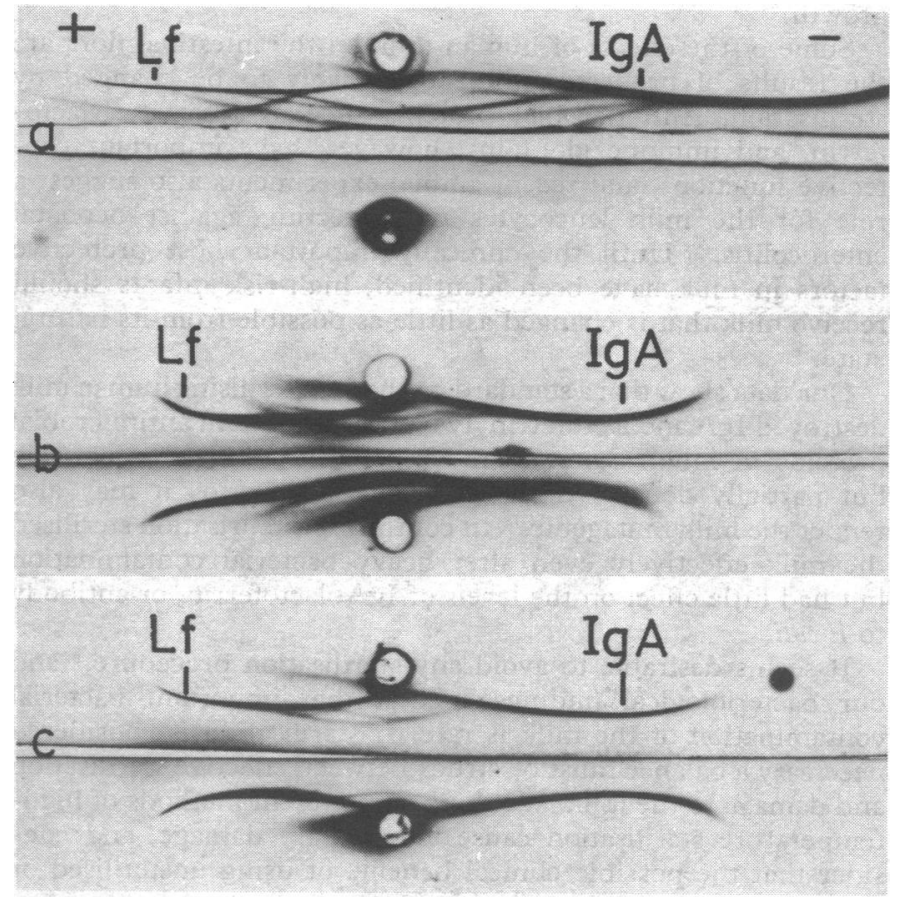

Immunoelectrophoresis of human milk before and after sterilisation. In each plate unsterilised sample is shown in top well. In lower wells each sample is shown (a) after sterilisation at $105^{\circ} \mathrm{C} ;(b)$ after gamma-irradiation; (c) after pasteurisation. $\mathbf{L f}=\mathbf{L a c t o f e r r i n}$.

of lower molecular weight than the native lactoferrin molecule. There was no detectable change in the immunoelectrophoretic pattern of 12 samples tested after pasteurisation (figure, $c$ ).

Haemagglutination titres for pooled $\mathrm{E}$ coli antigens-Eleven samples tested before conventional sterilisation had a mean $\log _{2}$ haemagglutination titre of 5 (equivalent to $1 / 32$ ). There was no haemagglutinating activity after sterilisation. Gamma-irradiation of a further 11 samples reduced the mean titre from 5.6 to 2. Pasteurisation did not reduce the titre by more than one dilution in any of 10 samples.

\section{Discussion}

Pooled expressed human milk is commonly used for feeding preterm infants who have a high risk of infection, ${ }^{2}$ although the clinical evidence that it provides protection is limited. ${ }^{\circ}$ The relative effectiveness of fresh and sterilised human milk has not been studied, although there is a suggestion that boiled human milk may be less effective than fresh milk in protecting against $E$ coli gastroenteritis. ${ }^{6}$

It is far from clear which factors in human milk are the most important for enhancing resistance against infection. It differs from cows' milk and cows' milk-based formulas in its carbohydrate, protein, and mineral composition as well as its buffering capacity, ${ }^{78}$ and these factors influence intestinal bacteria. ${ }^{8}$

TABLE II-Effect of conventional sterilisation, gamma-irradiation, and pasteurisation on $\operatorname{Ig} A$ and lactoferrin in human milk

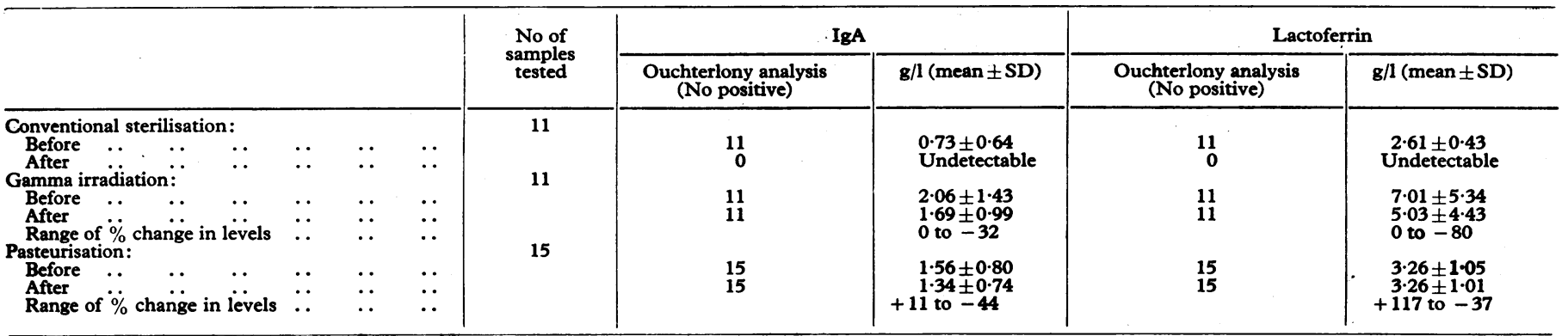


Many other constituents may influence bacterial and viral growth. ${ }^{9} 10$

Some of the effects of human milk on the intestinal flora are the results of properties that are unlikely to be changed by sterilisation. Antimicrobial proteins such as lysozyme, lactoferrin, and immune globulins, however, have important protective functions, and recent animal experiments also suggest a role for the milk leucocytes in protecting against neonatal enterocolitis. ${ }^{11}$ Until the clinically important host protective factors in milk have been identified, high-risk infants should receive milk that is changed as little as possible from its natural state.

Our data show that a standard method of sterilising human milk destroyed IgA and lactoferrin, two of the important antimicrobial proteins in milk. Gamma-irradiation also sterilised effectively but partially denatured the $\operatorname{IgA}$ and lactoferrin; it may also render the milk mutagenic. ${ }^{12}$ In contrast, pasteurisation sterilised the milk effectively even after heavy bacterial contamination but had little effect on the levels of IgA, lactoferrin, or antibody to $E$ coli.

It seems desirable to avoid any sterilisation procedure, ${ }^{8}$ and our bacteriological findings suggest that important bacterial contamination of the milk is rare. If sterilisation is considered necessary a balance must be struck between effective sterilisation and damage to the milk. We think that present methods of hightemperature sterilisation cause unnecessary damage, and consider that the possible clinical benefits of using unsterilised or pasteurised human milk for feeding infants at risk of infection should be further assessed.

We thank Miss M Taylor, Simpson Memorial Maternity Pavilion, Edinburgh, for arranging the supply of samples; Ethicon Limited, Edinburgh, for irradiating the samples; and Dr Forrester Cockburn, for his help and advice during this study.

\section{References}

${ }^{1}$ Robinson, M, Lancet, 1951, 1, 788.

${ }^{2}$ Cockburn, F, and Drillien, C M, (editors), Neonatal Medicine, p 298. Oxford, Blackwell, 1974.

${ }^{3}$ Newcomb, R W, Normansell, D, and Stanworth, D R, fournal of Immunology, 1968, 101, 905.

${ }^{4}$ Webster, A D B, Efter, T, and Asherson, G L, British Medical fournal, $1974,3,16$.

5 Tassovatz, B, and Kotsitch, A, Annales de Pédiatrie, 1961, 8, 285.

6 Svirsky-Gross, S, Annales Paediatrici, 1958, 190, 109.

7 Working Party of the Panel on Child nutrition, Committee on Medical Aspects of Food Policy. Present day practice in infant feeding. London, HMSO, 1974.

${ }^{8}$ Bullen, C L, and Willis, A T, British Medical fournal, 1971, 3, 338.

9 Goldman, A S, and Smith, C W, Fournal of Pediatrics, 1973, 82, 1082.

${ }^{10}$ Addy, D P, British Medical fournal, 1976, 1, 1268.

11 Pitt, J, et al, Pediatric Research, 1974, 8, 384.

12 Bhaskaram, C, and Sadasivan, G, American fournal of Clinical Nutrition, 1975, 28, 130.

(Accepted 21 October 1976)

\title{
Lumbar epidural analgesia in labour: relation to fetal malposition and instrumental delivery
}

\author{
I J HOULT, A H MACLENNAN, L E S CARRIE
}

British Medical fournal, 1977, 1, 14-16

\section{Summary}

The incidence of instrumental delivery and malposition immediately before delivery was compared in patients who were given lumbar epidural analgesia and those who were not. Instrumental delivery was five times more common and a malposition of the fetal head was more than three times as common in the epidural group as in women who did not receive regional analgesia. Similar incidences were found even when the epidural was electively chosen before labour in the absence of medical indications. The instrumental delivery rate was affected by parity, the length of the second stage of labour, and the return' of sensation by the second stage but not by other factors studied. The high incidence $(20 \%)$ of malposition associated with epidural analgesia was not affected by any of the factors studied.

The psychological and physical disadvantages of malposition and instrumental delivery have yet to be

John Radcliffe Hospital, Headington, Oxford

I J HOULT, MB, BS, senior house officer, obstetrics

A H MACLENNAN, MB, MRCOG, Nuffield lecturer in obstetrics

L E S CARRIE, MB, FFARCS, consultant anaesthetist

assessed. In the meantime, when there are no medical indications for epidural analgesia, the advantages of pain relief should be weighed against those of a normal spontaneous delivery.

\section{Introduction}

In Britain over the last 10 years there has been a rapid increase in the number of lumbar epidural blocks given in labour-a rate of $80 \%$ being reached in some units. ${ }^{1}$ This increase is associated with improved obstetric anaesthetic services and the advantages of epidural analgesia in labour-pain relief, ${ }^{2}$ the control of hypertension, the lessening of fetal metabolic acidosis ${ }^{3}$ in breech $^{2}$ and multiple delivery, ${ }^{2}$ etc. This change in obstetric management has led to a considerable increase in the number of instrumental deliveries. ${ }^{4}$ The incidence of associated malposition has been stated as being increased ${ }^{6}$ and unchanged. ${ }^{7} 8$

This prospective study was designed to investigate the incidence of malposition at the end of the second stage of labour and the incidence of instrumental delivery associated with lumbar epidural analgesia. Patients receiving epidural analgesia and who had no predisposing reason to require instrumental delivery or to have a malposition of the fetal head acted as a control group. Other factors that might influence the type of delivery were also analysed in an attempt to determine the best conditions for the induction of epidural analgesia associated with the highest incidence of spontaneous delivery. 